\title{
Article \\ A Complementary and Revised View on the N-Acylation of Chitosan with Hexanoyl Chloride
}

\author{
Berthold Reis ${ }^{1,2}$, Niklas Gerlach ${ }^{1}$, Christine Steinbach ${ }^{1}$, Karina Haro Carrasco ${ }^{1}$, Marina Oelmann ${ }^{1}$, \\ Simona Schwarz ${ }^{1}\left[\right.$, Martin Müller ${ }^{1,2}$ and Dana Schwarz ${ }^{1, *}$ \\ 1 Leibniz-Institut fuer Polymerforschung Dresden e.V., Hohe Straße 6, 01069 Dresden, Germany; \\ reis@ipfdd.de (B.R.); gerlach@ipfdd.de (N.G.); steinbach@ipfdd.de (C.S.); haro@ipfdd.de (K.H.C.); \\ oelmann@ipfdd.de (M.O.); simsch@ipfdd.de (S.S.); mamuller@ipfdd.de (M.M.) \\ 2 Department Chemistry and Food Chemistry, Technische Universität Dresden, 01062 Dresden, Germany \\ * Correspondence: schwarz-dana@ipfdd.de; Tel.: +49-351-46-58-542
}

Citation: Reis, B.; Gerlach, N.;

Steinbach, C.; Haro Carrasco, K.;

Oelmann, M.; Schwarz, S.; Müller, M.

Schwarz, D. A Complementary and Revised View on the N-Acylation of Chitosan with Hexanoyl Chloride. Mar. Drugs 2021, 19, 385. https:// doi.org/10.3390/md19070385

Academic Editor: Hitoshi Sashiwa

Received: 30 April 2021

Accepted: 28 June 2021

Published: 2 July 2021

Publisher's Note: MDPI stays neutral with regard to jurisdictional claims in published maps and institutional affiliations.

Copyright: (c) 2021 by the authors. Licensee MDPI, Basel, Switzerland. This article is an open access article distributed under the terms and conditions of the Creative Commons Attribution (CC BY) license (https:/ / creativecommons.org/licenses/by/ $4.0 /)$.

\begin{abstract}
The modification of the biobased polymer chitosan is a broad and widely studied field Herein, an insight into the hydrophobization of low-molecular-weight chitosan by substitution of amino functionalities with hexanoyl chloride is reported. Thereby, the influence of the $\mathrm{pH}$ of the reaction media was investigated. Further, methods for the determination of the degree of substitution based on ${ }^{1} \mathrm{H}-\mathrm{NMR}, \mathrm{FTIR}$, and potentiometric titration were compared and discussed regarding their accuracy and precision. ${ }^{1} \mathrm{H}-\mathrm{NMR}$ was the most accurate method, while FTIR and the potentiometric titration, though precise and reproducible, underlie the influence of complete protonation and solubility issues. Additionally, the impact of the $\mathrm{pH}$ variation during the synthesis on the properties of the samples was investigated by $\mathrm{Cd}^{2+}$ sorption experiments. The adjusted $\mathrm{pH}$ values during the synthesis and, therefore, the obtained degrees of substitution possessed a strong impact on the adsorption properties of the final material.
\end{abstract}

Keywords: hexanoyl chitosan; chitosan modification; substitution degree; $\mathrm{pH}$ variation

\section{Introduction}

Chitosan and modifications thereof have been the target of a vast number of studies [1-6]. The driving force behind the great number of publications is the biodegradability of chitosan to non-toxic products, the high abundance of the raw biomaterial chitin, and the primary amino group yielding in various types of applications such as the medical sector, environmental protection, wastewater treatment, and agriculture, only to name some of the largest [7-9]. Thus, the deacetylation of chitin to chitosan is now performed on a large industrial scale. The determination of the degree of deacetylation, which defines the properties, has already been studied in detail by Weißpflog et al. [10]. However, one major drawback for the application of chitosan as an absorber is its solubility at low $\mathrm{pH}$.

To further improve and overcome those challenges, the properties of the fascinating polymer chitosan, various functional groups have been substituted to the primary amino group on the polymer backbone [11]. However, often the synthesis and subsequent analysis of such substitution reactions are rather complicated due to the amount of different functional groups in the polymer. In the current study, we focus on the N-acylation of chitosan attaching a hexanoyl group (also called caproyl chloride) to the amino functionality. The hexanoyl group on the chitosan backbone reduces the solubility of the polymer in acidic media, making it a suitable adsorber material at low $\mathrm{pH}$ ranges. Various synthetic routes have been reported, including the use of hexanoic acid anhydrides [7,12], hexanoic acid combined with carbodiimide hydrochloride [13], or hexanoyl chloride [14,15]. The majority is based on the use of organic solvents and higher temperatures. We chose the substitution with hexanoyl chloride conducted in water at room temperature, which minimizes costs. For the nucleophilic substitution reaction with hexanoyl chloride, the $\mathrm{pH}$ of the aqueous 
solution needs to be thoroughly adjusted. Thus far, for the substitution of hexanoyl chloride on chitosan, the $\mathrm{pH}$ of the reaction solution has always been adjusted to a $\mathrm{pH}$ of $7[14,16,17]$.

In this study, we show that the substitution degree is extremely sensitive to the $\mathrm{pH}$ of the solution and therefore needs to be carefully adjusted in order to obtain reproducible products. The issue of profound characterization of the modified chitosan has also been addressed in several studies $[10,11,18]$. Thereby, several innovative methodologies using picric acid [19] or ninhydrin essay [20] have been developed. Herein, we focus on standard analytics, in particular ${ }^{1} \mathrm{H}-\mathrm{NMR}$, IR-spectroscopy, and potentiometric titration. The substitution degree was calculated with all three methods, and the comparability, as well as reliability, were discussed. Additionally, we investigated the influence of the initial $\mathrm{pH}$ on the spatial structure. Further, we conducted proof-of-concept adsorption experiments with $\mathrm{CdSO}_{4(\mathrm{aq})}$, which displayed the significant influence even small $\mathrm{pH}$ changes during the reaction synthesis have on the final adsorption performance.

\section{Results and Discussion}

Low molecular weight chitosan with an acetylation degree (DS\% ${ }_{\text {ACETYL }}$ ) of $10 \%$ was modified with hexanoyl chloride. The synthesis is described in detail in Section 3.2. In brief, Ch90/60/A1 was dissolved in $0.12 \mathrm{M}$ acetic acid, and the $\mathrm{pH}$ of the reaction solution was carefully adjusted to $\mathrm{pH} 6.0,6.5,7.0,7.5$, and 8.0, respectively. Hexanoyl chloride was added dropwise to the solution and was stirred for $16 \mathrm{~h}$ at r.t. Subsequently, the mixture was neutralized, poured into acetone (see images in Supporting Information (SI), Figure S1), filtered, and washed with methanol at $60^{\circ} \mathrm{C}$. In the course of the reaction, the amino functionality was partially substituted by the acyl chloride (Scheme 1 ). All yielded products are referred to as Hexanoyl-chitosan (H-chitosan), and for specification, the $\mathrm{pH}$ value is added (e.g., H-chitosan-7.5). The appearance of the samples varies with the increasing $\mathrm{pH}$ of the reaction solution, from compact agglomerates to finer particles (see Figure S2). This indicates variations in chemical (e.g., DS\%) and physical properties (e.g., TGA, Viscosity, XRD).

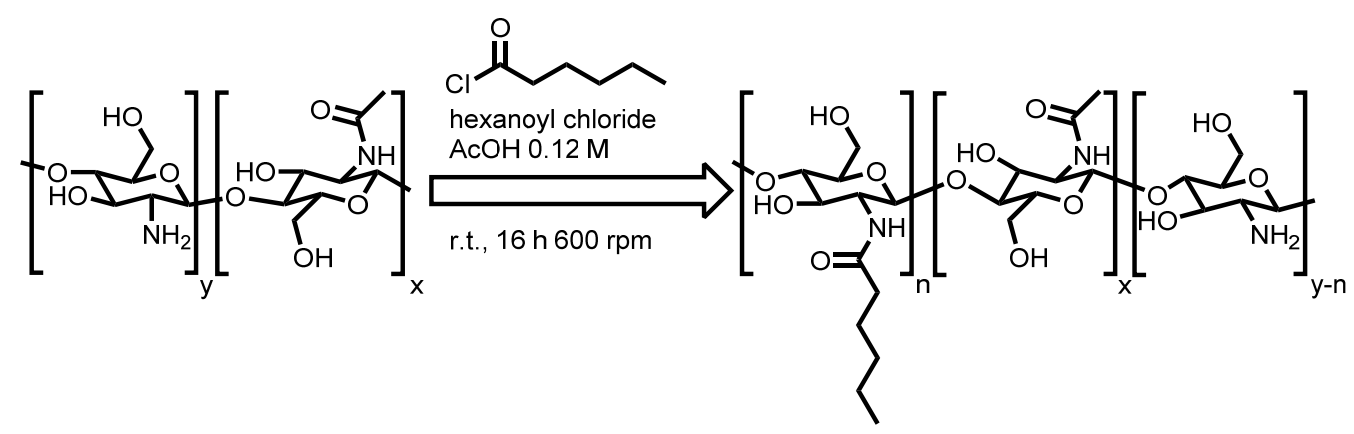

Scheme 1. Reaction scheme of the hexanoyl substitution on chitosan.

\subsection{Characterization of the H-Chitosan Samples}

To determine the chemical composition and the degree of substitution (DS\%, constitutional repeating unit $\mathrm{n}$ in Scheme 1) of the modified chitosan ${ }^{1} \mathrm{H}-\mathrm{NMR}, \mathrm{FTIR}$-spectroscopy measurements, zeta potential, and potentiometric titration were conducted. The DS\% was calculated for each method. The obtained values were compared and discussed. Further, the influence of the substitution on the physical properties was investigated by XRD, viscosity experiments, and nitrogen sorption as well as DLS for colloidal stability measurements.

For the analysis with ${ }^{1} \mathrm{H}-\mathrm{NMR}, \mathrm{Ch} 90 / 60 / \mathrm{A} 1$ and the five $\mathrm{H}$-chitosan samples were dissolved in $0.1 \mathrm{M} \mathrm{DCl}$ in $\mathrm{D}_{2} \mathrm{O}$ solution (Figure 1). All shifts were assigned to their corresponding protons in accordance with the literature [21]. The peaks at $4.89 \mathrm{ppm}$ and 4.52-4.67 ppm are attributed to the $\mathrm{H}-1^{\beta}$ and the $\mathrm{H}-1^{\alpha}$ proton of the deacetylated and acylated glucosamine in all spectra, respectively. Further, both native and the H-chitosan samples exhibited similar peaks in the region of $3.50-4.00 \mathrm{ppm}$ assigned to the protons ranging from $\mathrm{H}-3$ to $\mathrm{H}-6$ and the $\mathrm{H}-2$ bond to amid functionalities. The $\mathrm{H}-2$ coupled to an 
amino functionality is shifted upfield to $3.12-3.28 \mathrm{ppm}$. The $\mathrm{CH}_{3}$ peak related to the native acetylation of the chitosan is located at $2.02 \mathrm{ppm}$. Through integration and referencing to the H-1 peak areas, an acetylation degree (DS\% $\%_{\text {Acetyl }}$ ) of 10\% was calculated for Ch90/60/A1 (Equation (1), Section 3.4.1), confirming the data of the provider $\left(\mathrm{DS} \%_{\mathrm{ACETYL}}=10 \%\right.$ ). The spectra of the $\mathrm{H}$-chitosan samples further show hexanoyl-related peaks at $0.83 \mathrm{ppm}$ $\left(-\mathrm{CH}_{3}\right), 1.27 \mathrm{ppm}$ (different $-\mathrm{CH}_{2}$, ) and $1.54 \mathrm{ppm}\left(-\mathrm{CH}_{2}\right)$. The peak at $2.26 \mathrm{ppm}$ originates from the $-\mathrm{CH}_{2}$ group nearest to the carbonyl and is therefore subjected to proton-deuterium exchange (peaks between 2.12 and $2.18 \mathrm{ppm}$ ).

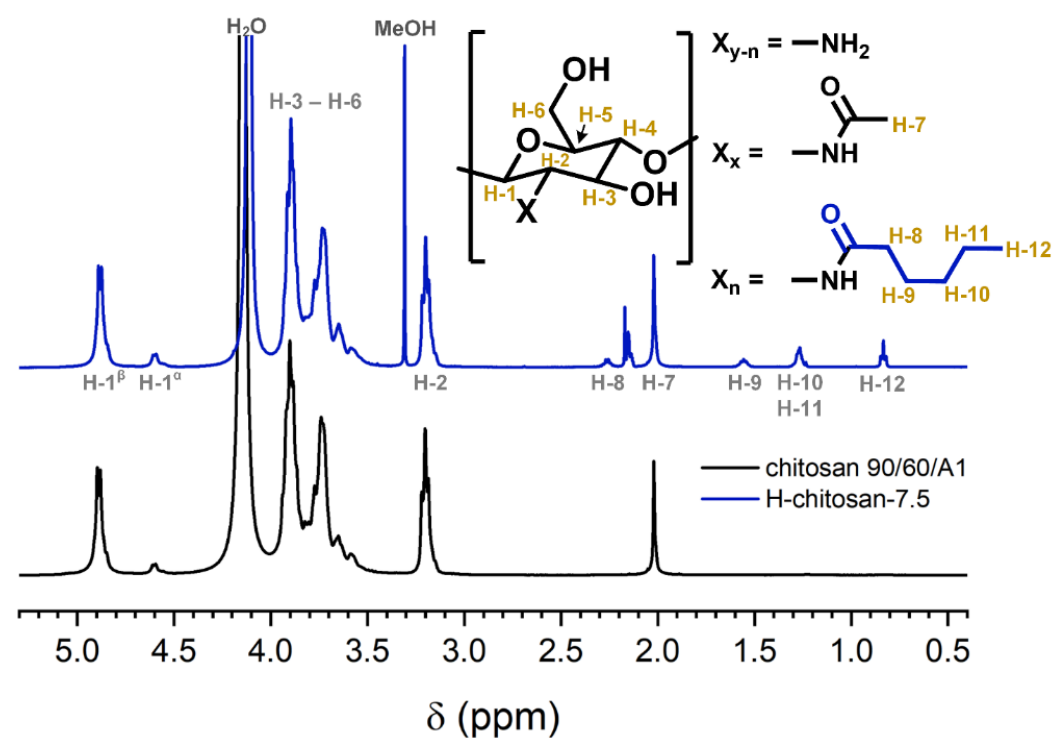

Figure 1. ${ }^{1} \mathrm{H}$ NMR spectra of native chitosan 90/60/A1 (black) and H-chitosan-7.5 (blue) with peak assignments to corresponding protons $\left(\mathrm{H}-1^{\alpha}\right.$ and $\mathrm{H}-1^{\beta}$ for anomeric structures, see Scheme S3). The ${ }^{1} \mathrm{H}$ NMR spectra of H-chitosan-6.0, H-chitosan-6.5, H-chitosan-7.0, H-chitosan-7.5, and $\mathrm{H}$ chitosan-8.0 are shown in Figure S3.

For the five H-chitosan samples, the DS\% ${ }_{\text {NMR }}$ was calculated by using the peak areas of $\mathrm{H}-1^{\beta}$ and the $\mathrm{H}-1^{\alpha}$, since these signals are not subjected to overlap (Table 1, Equation (2), Section 3.4.1). The NMR spectra with integrals are given in the supporting information (Figure S3).

Table 1. NMR- and FTIR-based calculation of the substitution degree DS\% for the H-chitosan samples.

\begin{tabular}{|c|c|c|c|}
\hline H-Chitosan & DS\%NMR * & DS $\%_{\text {FTIR-1 }} * *$ & DS\%FTIR-2 $* * *$ \\
\hline H-chitosan-6.0 & $1.6 \%$ & $16.6 \%$ & $2.9 \%$ \\
\hline H-chitosan-6.5 & $2.1 \%$ & $20.8 \%$ & $1.8 \%$ \\
\hline H-chitosan-7.0 & $2.7 \%$ & $20.1 \%$ & $5.3 \%$ \\
\hline H-chitosan-7.5 & $3.0 \%$ & $19.9 \%$ & $3.8 \%$ \\
\hline H-chitosan- 8.0 & $2.9 \%$ & $19.5 \%$ & $3.0 \%$ \\
\hline
\end{tabular}

* DS\%NMR calculated with $\mathrm{H}-1$ proton signals $\left(\mathrm{H}-1^{\alpha}+\mathrm{H}^{\beta}{ }^{\beta}\right)$ as reference; ${ }^{* *} \mathrm{DS} \%_{\mathrm{FTIR}-1}$ calculated using method 1 (Equation (3), Section 3.4.2); *** DS\%FTIR-2 calculated using method 2 (Equations (4)-(7), Section 3.4.2).

The increase in the $\mathrm{DS} \%{ }_{\mathrm{NMR}}$ when increasing the $\mathrm{pH}$ of the reaction media from 6.0 to 7.5 can be explained by the increased neutralization of the byproduct hydrochloric acid at higher $\mathrm{pH}$ values, which shifts the reaction equilibrium toward the desired product. This effect seems to cease when surpassing the $\mathrm{pH}$ value of 7.5 due to the larger part of precipitated chitosan, which takes more time to dissolve while the $\mathrm{pH}$ drops during the course of the reaction. Furthermore, this kinetically favors the hydrolysis of hexanoyl chloride to hexanoic acid as a side reaction (see Scheme S1). Thus, a higher $\mathrm{pH}$ value should accelerate this hydrolysis. For a precise NMR analysis and subsequent DS\% ${ }_{N M R}$ 
calculation, the existence of potential byproducts such as hexanoic acid needs to be precluded. However, in the ${ }^{1} \mathrm{H}$ NMR spectra, no carboxylic acid peak corresponding to the potential byproduct hexanoic acid at $2.16 \mathrm{ppm}, 1.28 \mathrm{ppm}$, and $0.86 \mathrm{ppm}$ was observed [22] These hexanoic acid peak shifts slightly differ from their corresponding $\mathrm{CH}_{2}$ or $\mathrm{CH}_{3}$ group in the hexanoyl functionality. The spin multiplicity of the hexanoyl functionality was well resolved, suggesting that no corresponding peaks of hexanoic acid are underlying those of the attached functionalization. Therefore, no residual hexanoic acid from the hydrolysis (see Scheme S1) remained within the samples.

Further, the potential cleavage of the amide under the conditions within the NMR tube $\left(90{ }^{\circ} \mathrm{C}, 0.1 \mathrm{M} \mathrm{DCl}\right)$ (see Scheme S2) can be precluded. Additionally, it is known that such reactions only occur in severe conditions, e.g., with acids in significantly higher concentrations [23]. Hence, NMR is a very valid and accurate method to determine the DS\% of H-chitosan samples.

A complementary method for the determination of functional groups and the DS is attenuated total reflection (ATR) Fourier transform infrared (FTIR) spectroscopy. Thereby, two methods and calculation strategies were applied and compared.

ATR-FTIR spectra on the powdered samples were recorded and evaluated according to the method (i.e., method 1) of Le Tien et al. [14], which is based on a study of Moore et al. [24]. For both $\mathrm{H}$-chitosan samples and the native chitosan, prominent bands between 3600 and $3100 \mathrm{~cm}^{-1} v(\mathrm{OH})$ due to hydroxyl groups and bound water, at $2918 \mathrm{~cm}^{-1}$ and $2879 \mathrm{~cm}^{-1} v\left(\mathrm{CH}_{2}\right)$ due to hydrocarbon moieties, at $1655 \mathrm{~cm}^{-1}$ (shoulder) and $1588 \mathrm{~cm}^{-1}$ (Amide I and II, respectively), at $1510 \mathrm{~cm}^{-1}\left(\delta\left(\mathrm{NH}_{3}{ }^{+}\right)\right)$due to ammonium groups and at $1080 \mathrm{~cm}^{-1}(v(\mathrm{C}-\mathrm{O}))$ due to $\mathrm{C}-\mathrm{O}-\mathrm{H}$ and $\mathrm{C}-\mathrm{O}-\mathrm{C}$ linkages in polysaccharides were obtained (Figure $\mathrm{S} 4$ ).

The DS\%FTTR-1 was calculated according to Le Tien et al. [14] (see method 1, Equation (3), Section 3.4.2), yielding a DS\% FTTR-1 value of $19.9 \%$ for H-chitosan-7.5. Thus, the determined DS\% FTTR-1 value is more than six times larger than the DS\% $\%_{N M R}$ value. The other $\mathrm{H}$-chitosan samples feature a similar trend. It has to be noted that this evaluation method is based on the ratio of the Amide I band and the $v(\mathrm{OH})$ band. The Amide I overlaps with $\delta(\mathrm{OH})$ of water $\left(1640 \mathrm{~cm}^{-1}\right)$, and the $v(\mathrm{OH})$ is composed of contributions of hydroxyl groups of chitosan and bound water. Both influences are inclined to falsify the calculation.

Based on the results from method 1, ATR-FTIR spectra of all samples were recorded again by casting a thin film of each sample on the ATR crystal (Figure 2 for H-chitosan-7.5, Figure S5 for all). To reduce the influence of the water band, the film was carefully dried and subsequently constantly purged with nitrogen during measurement. Since thin films are more accessible for drying through nitrogen than compact powders are, with this way of sample preparation, the exclusion of water can be ensured more effectively. For the evaluation of the thin film ATR-FTIR spectra, a modified method (method 2) was followed, which is based on the ratio $(\mathrm{Q})$ between integrals of the Amide I band at $1655 \mathrm{~cm}^{-1}$ (determined via line shape analysis (LSA) Figure S6) and the $v(C-O)$ band at $1080 \mathrm{~cm}^{-1}$ $\left(\mathrm{Q}=\mathrm{I}_{\text {Amide }} / \mathrm{I}_{\mathrm{SACC}}\right)$. The ratio of the native chitosan $\left(\mathrm{Q}_{\mathrm{CHIT}}\right)$ was determined and a normalization factor $(n)$ was calculated by using the known acetylation degree (DS\% ${ }_{\text {ACETYL }}$ ) of $10 \%$. The corresponding (higher) ratio $\mathrm{Q}_{\mathrm{H}-\mathrm{CHIT}}$ of the H-chitosan samples is used to calculate the total substitution degree (DS\% оОтAL), which includes the hexanoyl and the acetyl-related Amide I signals. The substitution degree DS\%FTIR-2 was determined from

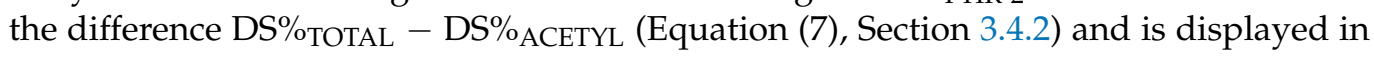
Table 1. In general, the yielded DS\%FTIR-2 values correlated with the DS\%NMR with an average deviation of $\pm 1.0 \%$ (Table 1, Figure S7). The majority of the DS\%FTIR-2 were above the values determined by NMR. Presumably, there is still residual water in the dried film samples, and the corresponding $\delta(\mathrm{OH})$ band intensity might contribute to that of the Amide I band. Nonetheless, this novel method poses a significant improvement to method 1 with several advantages. First, it is not based on the questionable $v(\mathrm{OH})$ intensities (see above). Second, it uses line-shape analysis for the determination of the integral of the Amide I band. Further, the thin films are more susceptible to nitrogen drying. Altogether, this leads 
to an improved reduction of falsifying water influences. Therefore, this procedure can be considered as a suitable method for fast overview measurements.

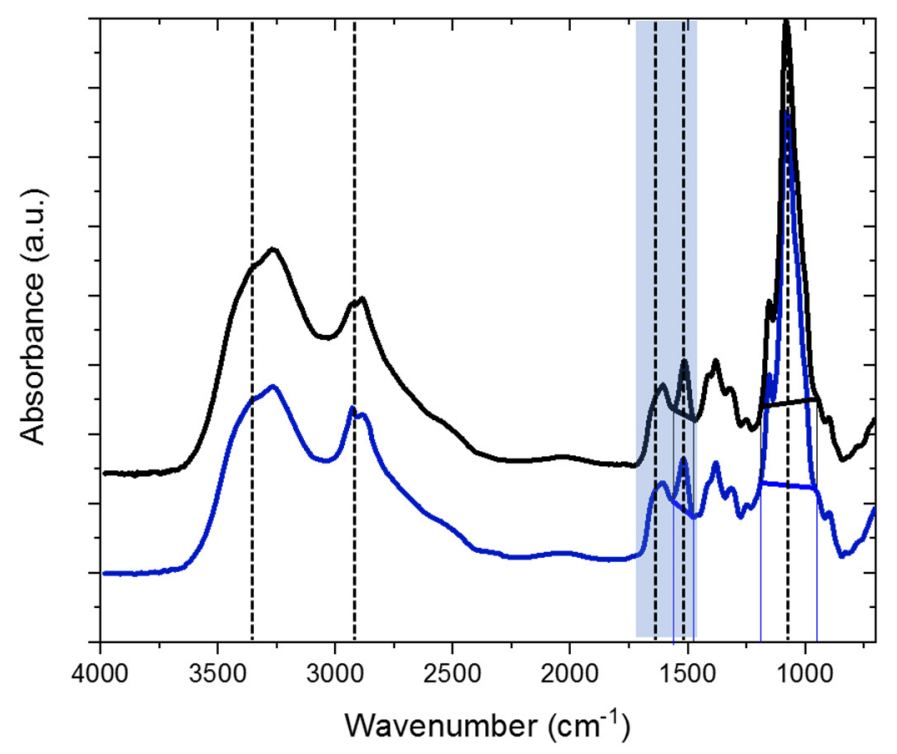

Figure 2. ATR-FTIR spectra of thin films of native chitosan 90/60/A1 (black) and H-chitosan-7.5 (blue) with diagnostic IR bands (left to right): $v \mathrm{OH}, v \mathrm{CH}_{2}$, Amide I, $\delta\left(\mathrm{NH}_{3}{ }^{+}\right), v(\mathrm{C}-\mathrm{O})$, blue area subjected to LSA (all H-chitosan spectra in Figure S5).

Thermogravimetric analysis showed a bimodal disintegration for the low molecular weight $\left(\mathrm{M}_{\mathrm{w}}=90-150 \mathrm{kDa}\right)$ native chitosan, with the first decomposition step ranging from about $180^{\circ} \mathrm{C}$ to $390{ }^{\circ} \mathrm{C}$ and the second ranging from $390{ }^{\circ} \mathrm{C}$ to $470{ }^{\circ} \mathrm{C}$ (Figure S8). The Hchitosan samples exhibited a similar primary decomposition step ranging from $180{ }^{\circ} \mathrm{C}$ to $580^{\circ} \mathrm{C}$. However, the second step differs from that of the native chitosan, ranging up to $650^{\circ} \mathrm{C}$. Further, within this second step, a third and smaller one is located within the $\mathrm{H}$-chitosan functions. This step ranges from $420^{\circ} \mathrm{C}$ to $475{ }^{\circ} \mathrm{C}$ and is larger for the higher DS\%. Overall, the thermal stability was increased by the substitution.

Further, the zeta potential in the dependency of the $\mathrm{pH}$ was investigated. This method provides information on the surface charge at specific $\mathrm{pH}$ values, which is of great importance for absorber materials, for example. To test the influence of the ionic strength, a similar approach for titration was chosen. By dissolute the initial $1 \mathrm{~g} / \mathrm{L}$ solution with a $\mathrm{pH}$ of 1 , solutions of $0.05 \mathrm{~g} / \mathrm{L}$ and $0.1 \mathrm{~g} / \mathrm{L}$ were obtained for native chitosan and $\mathrm{H}$-chitosan-7.5, respectively. The streamingpotential vs. $\mathrm{pH}$ curves are shown in Figure 3. In Figure 3a, the isoelectric point (IEP) for native chitosan and H-chitosan-7.5 for both concentrations (i.e., $0.05 \mathrm{~g} / \mathrm{L}$ and $0.1 \mathrm{~g} / \mathrm{L}$ ) was located around $\mathrm{pH}$ 7.2. Additionally, the different H-chitosan samples were compared using only $0.05 \mathrm{~g} / \mathrm{L}$ solutions (Figure $3 \mathrm{~b}$ ). All IEPs are located at $7.0 \pm 0.1$. This indicates that low absolute deviations in DS\% of $1-2 \%$ have little to no influence on the IEP.

Another fast and versatile method to determine the DS\%pot is potentiometric titration, whereby positively charged amino functionalities are complexed by the short polyanion sodium polyethylene sulfonate (NaPES). Lin et al. provided an equation (Equation (8), Section 3.4.3) to calculate the DS\% To investigate the influence of $\mathrm{pH}$ and ionic strength, different dissolutions from the initial solution of $1 \mathrm{~g} / \mathrm{L}$ at $\mathrm{pH}_{0} 1$ were prepared. Thus, three solutions with concentrations of $0.01 \mathrm{~g} / \mathrm{L}, 0.05 \mathrm{~g} / \mathrm{L}$, and $0.1 \mathrm{~g} / \mathrm{L}$ were prepared, and their respective $\mathrm{pH}_{\text {dis }}$ were recorded.

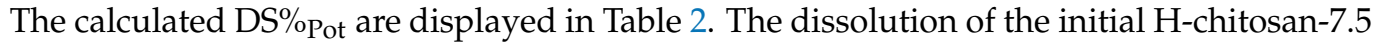
solution yielded different $\mathrm{pH}_{\text {dis }}$ values for the three different concentrations. The calculated DS $\%_{\text {pot }}$ for the three solutions varies by $\pm 0.1 \%$, which shows a low influence of the pHdis. This is due to the already fully protonated chitosan, as shown in the streamingpotential vs. 
pH curve. Both charge densities of the chitosan 90/60/A1 and the H-chitosan-7.5 show consistency within concentrations of 0.05 and $0.10 \mathrm{~g} / \mathrm{L}$. At $0.01 \mathrm{~g} / \mathrm{L}$, the concentration was not high enough for accurate measurements. Thus, $0.05 \mathrm{~g} / \mathrm{L}$ was chosen for the following more extensive investigations.
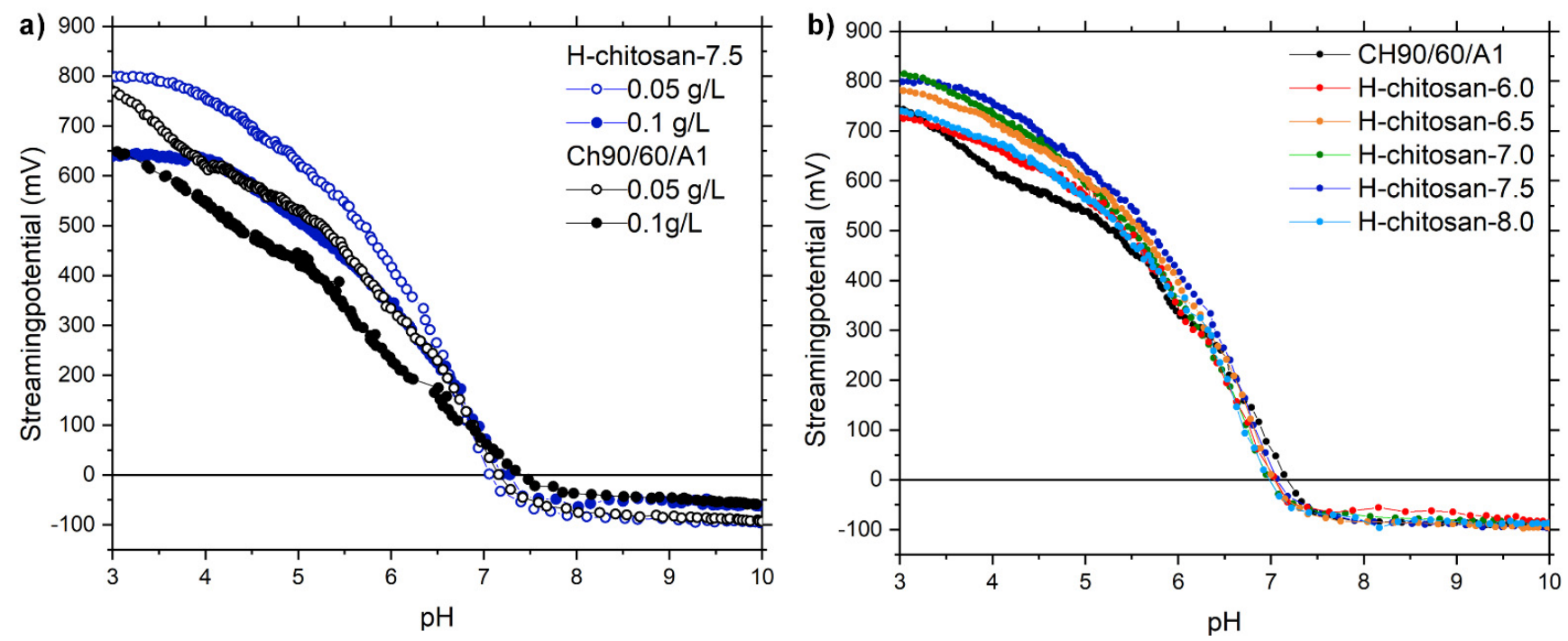

Figure 3. Streamingpotential vs. $\mathrm{pH}$ for (a): native chitosan 90/60/A1 at $0.05 \mathrm{~g} / \mathrm{L}$ (black, open sphere), $0.1 \mathrm{~g} / \mathrm{L}$ (black, full sphere), H-chitosan-7.5 at $0.05 \mathrm{~g} / \mathrm{L}$ (blue, open sphere), and at $0.1 \mathrm{~g} / \mathrm{L}$ (blue, full sphere). Streamingpotential vs. $\mathrm{pH}$ at $0.05 \mathrm{~g} / \mathrm{L}$ for (b): native chitosan 90/60/ A1 (black), H-chitosan-6.0 (red), H-chitosan-6.5 (orange), H-chitosan-7.0 (green), H-chitosan-7.5 (blue), H-chitosan-8.0 (light blue).

Table 2. Titration of chitosan 90/60/A1 and H-chitosan-7.5 with NaPES for two different concentrations and respective pH values. The stock solution featuring an initial $\mathrm{pH}$ of $1\left(\mathrm{pH}_{0}\right)$ was diluted with ultrapure water yielding in the $\mathrm{pH}_{\text {dis }}$.

\begin{tabular}{ccccccc}
\hline Concentration & $\mathbf{p H}_{\mathbf{0}}$ & $\mathbf{p H}_{\text {dis }} \mathbf{9 0 / 6 0 / A 1}$ & $\begin{array}{c}\mathbf{p H}_{\text {dis }} \\
\text { H-Chitosan-7.5 }\end{array}$ & $\begin{array}{c}\mathbf{c}(\mathbf{m m o l} / \mathbf{L}) \\
\mathbf{9 0 / 6 0 / A 1}\end{array}$ & $\begin{array}{c}\mathbf{c}(\mathbf{m m o l} / \mathbf{L}) \\
\text { H-Chitosan-7.5 }\end{array}$ & DS\%Pot-1 \\
\hline $0.01 \mathrm{~g} / \mathrm{L}$ & 1.0 & 2.9 & 2.9 & 6.2 & 5.4 & $8.7 \%$ \\
$0.05 \mathrm{~g} / \mathrm{L}$ & 1.0 & 2.2 & 2.2 & 5.8 & 5.0 & $8.6 \%$ \\
$0.10 \mathrm{~g} / \mathrm{L}$ & 1.0 & 2.0 & 2.0 & 5.7 & 5.0 & $8.8 \%$ \\
\hline
\end{tabular}

For all H-chitosan samples, the observed DS\%pot-1 was significantly higher (5.6-8.1\% higher) than the corresponding DS\% ${ }_{\mathrm{NMR}}$ (compare Table SI 1). This may be based on the hindrance of the complex arrangement through "trapping" of the amino functionalities within hydrophobic domains. The increase in hydrophobicity leads to a reduction of the solubility by reducing the number of protonable amino functionalities and enabling selfaggregation in the solution. Although this may be beneficial regarding applications such as drug delivery, it complicates potentiometric titration as an analytical method. Commonly, native chitosan dissolved with $\mathrm{HCl}_{(\mathrm{aq})}$ at r.t. with a magnetic stirrer for $24 \mathrm{~h}$. The optimum $\mathrm{pH}$ to dissolve $\mathrm{H}$-chitosan is at $\mathrm{pH} 1$ (after stirring $24 \mathrm{~h}$ at r.t.). However, since this modified chitosan is poorly soluble, there are some larger particles in the solution, which are visible to the naked eye. For potentiometric titration, the solubility of samples the is a significant factor. Hence, to investigate this parameter by improving the solubility, in a second attempt, the samples were stirred at $50{ }^{\circ} \mathrm{C}$ for $24 \mathrm{~h}$ and then treated with an ultrasonic bath for $2 \mathrm{~h}$. The DS\% pot-2 was calculated via the same equation (Equation (8), Section 3.4.3) and compared in Table 3.

The DS\% $\%_{\text {Pot-2 }}$ values were, on average, about $0.9 \%$ closer to the DS\% ${ }_{\mathrm{NMR}}$ determined with NMR. Nevertheless, the determined values are still about two to three times as high 
as the DS\% $\%_{N M R}$, which is why this method again is more suitable for quick overview measurements than profound investigation.

Table 3. Determined DS\% $\%$ ot of the H-chitosan solutions $(0.05 \mathrm{~g} / \mathrm{L})$ with different methods of dissolving chitosan at $\mathrm{pH} 1$ in $\mathrm{HCl}_{(\mathrm{aq})}$.

\begin{tabular}{|c|c|c|c|}
\hline H-Chitosan & DS\%NMR & DS\%Pot-1 * & DS $\%$ Pot-2 ** \\
\hline H-chitosan-6.0 & $1.6 \%$ & $8.2 \%$ & $6.9 \%$ \\
\hline H-chitosan-6.5 & $2.1 \%$ & $9.8 \%$ & $9.9 \%$ \\
\hline H-chitosan-7.0 & $2.7 \%$ & $10.8 \%$ & $11.1 \%$ \\
\hline H-chitosan-7.5 & $3.0 \%$ & $8.6 \%$ & $7.7 \%$ \\
\hline H-chitosan-8.0 & $2.9 \%$ & $8.5 \%$ & $6.0 \%$ \\
\hline
\end{tabular}

To further investigate the self-aggregation properties in solution, all solved samples were investigated by dynamic light scattering (DLS) measurements. For the samples solved at r.t. for $24 \mathrm{~h}$, the distributions are depicted in Figures S9-S11, whereby the larger, optically visual, non-solved particles were not captured by the method. The samples solved using the improved method $\left(50{ }^{\circ} \mathrm{C}, 24 \mathrm{~h}\right.$, ultrasonic bath for $2 \mathrm{~h}$ ) are shown in Figure 4. All chitosan samples featured a bimodal size distribution in the intensity curve, as shown in Figure 4a. The smaller particles were in the range of $10-40 \mathrm{~nm}$ in diameter, and the larger particles possessed particles diameters of several hundred nanometers. However, the volume and number curves clearly show just the small particles yielding in an extremely small ratio of larger particles shown in the intensity curve. Thus, the average particle sizes according to the number distribution were around $8 \mathrm{~nm}$ for H-chitosan-6.0, H-chitosan-6.5, and H-chitosan-7.0; around $10 \mathrm{~nm}$ for Ch90/60/A1; and around $18 \mathrm{~nm}$ for H-chitosan-7.5 and H-chitosan-8.0. H-chitosan-6.0, H-chitosan-6.5, and H-chitosan-7.0 featured smaller particles in comparison to the native chitosan because the solubility of the H-chitosan samples decreased. H-chitosan-7.5 and H-chitosan-8.0 exhibited the highest DS\% values, resulting in an increased agglomeration number of polymer chains per particle to further compensate for the decreased solubility. It is already known that H-chitosan samples form self-aggregated particle structures in aqueous conditions [26]. The influence of the $\mathrm{pH}$ of the solution on the particle size has already been studied by $\mathrm{Pa}$ and $\mathrm{Yu}$ [27]. The DLS intensity curves at $\mathrm{pH} 1.55$ are in agreement with the size distribution shown in Figure 4.

To investigate the spatial structure in a dry state, nitrogen sorption experiments and X-ray diffraction measurements were conducted (compare Sections 3.4.5 and 3.4.8). Thereby no significant specific surface area (SSA) was found either for the native chitosan or for the H-chitosan samples (Figure S12). Further, all X-ray diffraction patterns of the H-chitosan samples showed the same broad reflex at $2 \Theta=20^{\circ}$ as native chitosan (compare Figure S13), which indicated a long-range order and coincided with the literature [14]. A deviation is the small shoulders between $25^{\circ}$ and $30^{\circ} 2 \Theta$, which indicates a minor proportion of differently structured domains within the H-chitosan samples. Overall, both nitrogen sorption and X-ray diffraction suggest that the dry state structure of native and modified chitosan are very similar.

Viscosity and rheology properties were determined using an oscillating rotational rheometer (Section 3.4.9). As seen in Figure S14, the H-chitosans differ from native chitosan at lower velocity gradients of $0.011 / \mathrm{s}$ to $5.301 / \mathrm{s}$. In this region, the $\mathrm{H}$-chitosans flow, exhibiting more pronounced viscoelastic characteristics, whilst the native chitosan maintains more of a plateau at about $0.04 \mathrm{~Pa}$. A possible explanation is the breaking-up of the hydrogen bonds between the chitosan backbones through the hydrophobic hexanoyl moiety. The low substitution degrees would explain why no stabilization via hydrophobic domains took place. This coincides with the observation that all $\mathrm{H}$-chitosan exhibit very similar functions. Even the smallest DS\% of $1.6 \%$ for H-chitosan- 6.0 decreases the shear stress by several orders in magnitude. 

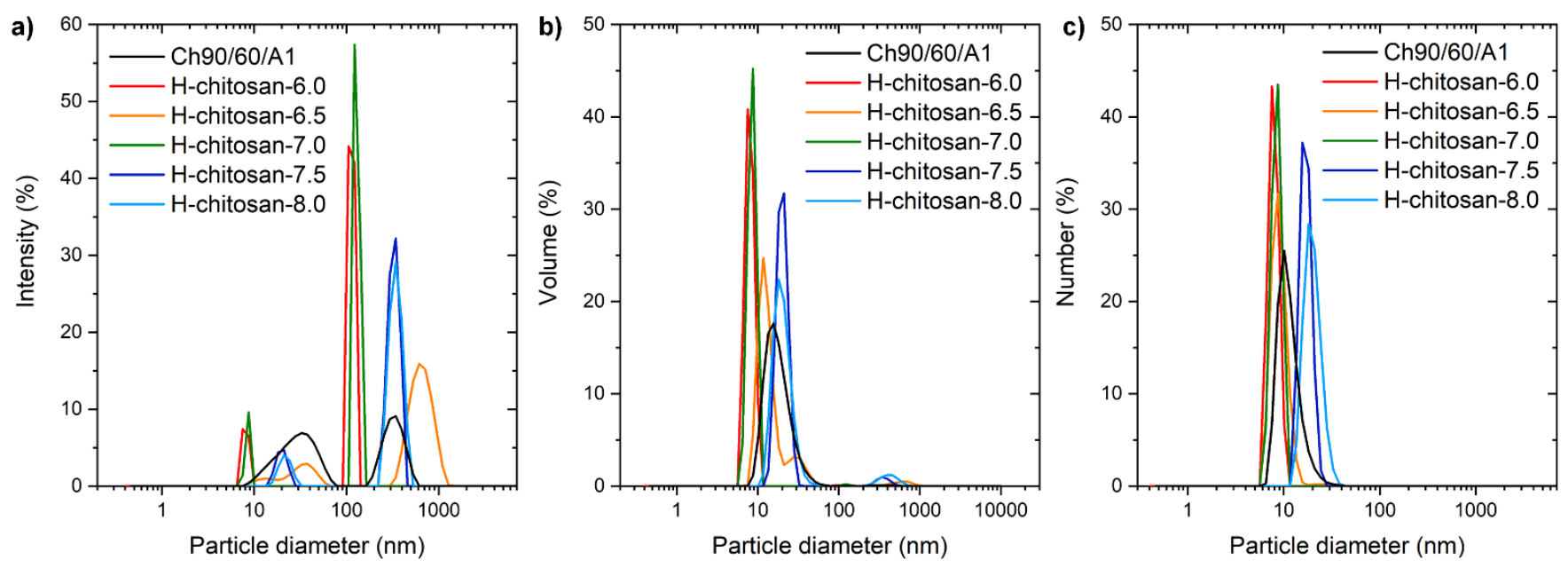

Figure 4. DLS-measurements of chitosan and $\mathrm{H}$-chitosan samples $\left(1 \mathrm{~g} / \mathrm{L}\right.$, at $\mathrm{pH}=1$, solved at $50{ }^{\circ} \mathrm{C}$ for $24 \mathrm{~h}$ with additional ultrasonic treatment for $2 \mathrm{~h}$ ) of native chitosan 90/60/A1 (black), H-chitosan-6.0 (red), H-chitosan-6.5 (orange), H-chitosan7.0 (green), H-chitosan-7.5 (blue), H-chitosan-8.0 (light blue) with (a): intensity distribution (b): volume distribution and (c): number distribution.

\subsection{Adsorption Experiments with $\mathrm{CdSO}_{4(a q)}$}

Chitosan is an extremely good adsorber for water treatment applications. Thus, chitosan adsorbs, for example, heavy metal ions in very high amounts [6]. To show the influence of the DS\% on the adsorption properties of H-chitosan, we investigated the adsorption of $\mathrm{Cd}^{2+}$ on the five diverse H-chitosan samples for two different concentrations. The H-chitosan samples were treated with initial concentrations of $0.037 \mathrm{mg} / \mathrm{L}$ and $0.295 \mathrm{mg} / \mathrm{L} \mathrm{Cd}^{2+}$, which corresponds to the 10 - and 100-fold value of the drinking water concentration limit [28]. H-chitosan-7.0, H-chitosan-7.5, and H-chitosan-8.0 featured the highest DS\% ${ }_{N M R}$ values and thus also higher adsorption rates for $\mathrm{Cd}^{2+}$ with values up to $90 \% \mathrm{Cd}^{2+}$ removal. Among those three $\mathrm{H}$-chitosan samples, the $\mathrm{DS} \% \mathrm{NMR}$ values vary marginally, yielding similarly high adsorption values. In comparison, H-chitosan- 6.0 with the lowest DS\%NMR value exhibited the lowest $\mathrm{Cd}^{2+}$ removal rates (Figure 5). The native chitosan features very good adsorption properties for $\mathrm{Cd}^{2+}$ removal with a distinct smaller standard deviation due to the homogeneity of the sample. $\mathrm{Cd}^{2+}$ is removed by chitosan due to complexation with the primary amino groups on the chitosan backbone [29]. Thus, although the samples are solid in this investigation, chitosan is swelling in water to a relatively large extent, which leads to a better complexation process with $\mathrm{Cd}^{2+}$. For comparison, the H-chitosan exhibited limited swelling properties (see viscosity measurements, Figure S14) due to the hexanoyl group. Furthermore, as shown in the DLS measurements, the particle size and agglomeration number of polymer chains per particle are dependent on the DS\% $\%_{N M R}$, resulting in different sorption properties.

Thus, even subtle differences in synthesis conditions, such as a $\mathrm{pH}$ difference of 0.5 , cause significant deviations in application; here, there is a $50-70 \%$ difference in adsorption of $\mathrm{Cd}^{2+}$ for H-chitosan-6.5 to H-chitosan-7.0. 


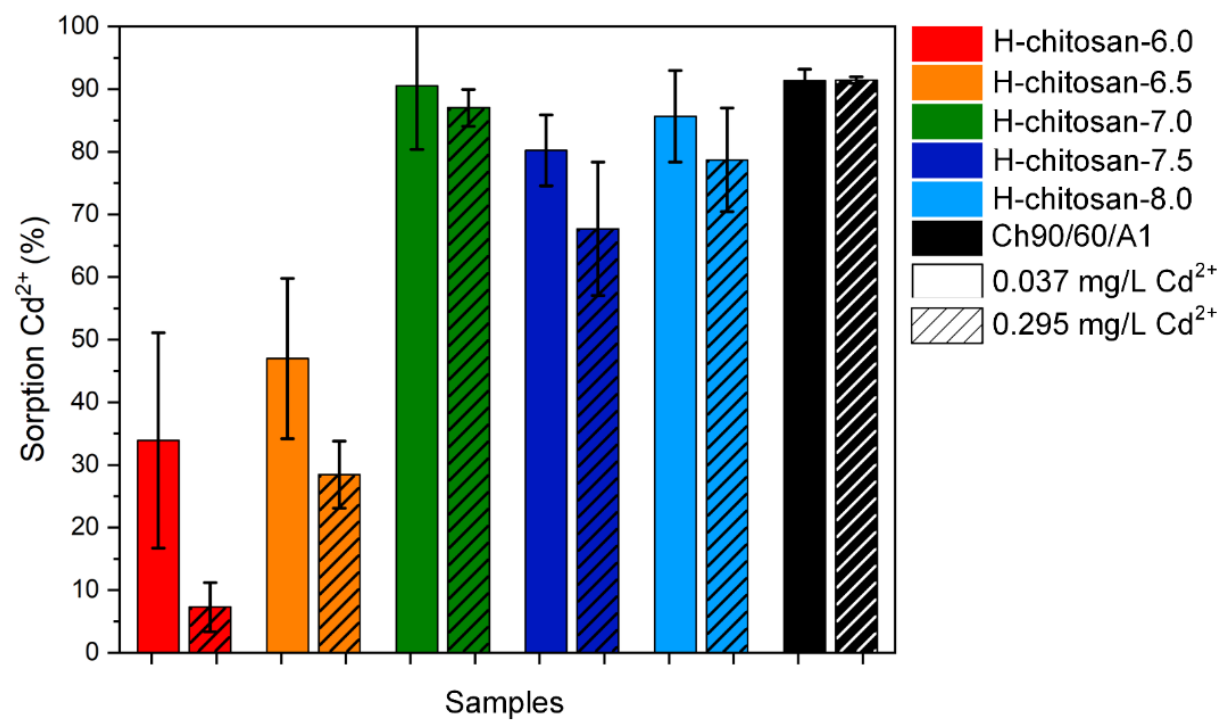

Figure 5. Adsorption of the different $\mathrm{H}$-chitosan samples using the initial $\mathrm{Cd}^{2+}$ concentrations of $0.037 \mathrm{mg} / \mathrm{L}$ (plain) and $0.295 \mathrm{mg} / \mathrm{L}$ (striped). The corresponding $\mathrm{pH}$ values of the solution before and after the adsorption as well as the $\mathrm{pH}$ values of the $\mathrm{H}$-chitosan samples in ultrapure water are shown in Figure S15.

\section{Materials and Methods}

\subsection{Materials}

The chitosan 90/60/A1 (origin crab shell, $\mathrm{M}_{\mathrm{w}}=90-150 \mathrm{kDa}$, manufacturer's specification) was purchased from Biolog Heppe ${ }^{\circledR} \mathrm{GmbH}$ (Landsberg, Germany) and used without further purification. The indexes relate to a deacetylation degree of $90 \%$, a viscosity of $60 \mathrm{mPas}$, and 1\% ash content. Hexanoyl chloride, hydrochloric acid (37\%), sodium hydroxide, and cadmium sulfate were purchased from Sigma Aldrich (Taufkirchen, Germany) and used without any further purification. Concentrated acetic acid was purchased from Merck KGaA (Darmstadt, Germany), whilst methanol and acetone were purchased from VWR (99\%) (Darmstadt, Germany). As adsorption and reaction media ultrapure water obtained by a Milli-Q Advantage A10 ${ }^{\circledR}$ system from Merck KGaA (Darmstadt, Germany), (TOC $5 \mathrm{ppb}$, resistivity of $18.2 \mathrm{M} \Omega^{*} \mathrm{~cm}$ at $25^{\circ} \mathrm{C}$ ) was used.

\subsection{Synthesis of H-Chitosan}

The synthesis is based on the method reported by Le Tien et al. [14]. A unit of $1.3 \mathrm{~g}$ of the purchased 90/60/ A1 chitosan was dissolved for $16 \mathrm{~h}$ in $175 \mathrm{~mL} 0.12 \mathrm{M}$ acetic acid. The $\mathrm{pH}$ value of the solution was adjusted to 6.0, 6.5, 7.0, 7.5, or 8.5 in separate experiments, with $2 \mathrm{M} \mathrm{NaOH}$ creating a slurry of partially precipitated chitosan. Special focus was directed towards this $\mathrm{pH}$ adjustment due to the longer equilibration times $(1-2 \mathrm{~h})$ of the system. Subsequently, hexanoyl chloride was added drop-wise with a mass ratio of 2:1 hexanoyl chloride/chitosan to the mixture, which was then stirred at $600 \mathrm{rpm}$ for $16 \mathrm{~h}$ at r.t. The $\mathrm{pH}$ of the clear reaction mixture was again adjusted to about 7 and then poured into $2 \mathrm{~L}$ of acetone. The slurry was filtered and washed with boiling methanol. The resulting product was then dried in an oven at $50{ }^{\circ} \mathrm{C}$ for several hours.

\subsection{Adsorption Experiments with $\mathrm{CdSO}_{4}$}

$100 \mathrm{mg}$ of the modified chitosan was weighted in a $50 \mathrm{~mL}$ centrifuge tube. A total of $30 \mathrm{~mL}$ of $\mathrm{Cd}^{2+}$ solution $(0.03 \mathrm{mg} / \mathrm{L}$ and $0.3 \mathrm{mg} / \mathrm{L}$, respectively) was added. After stirring $24 \mathrm{~h}$ with a magnetic stirrer at $400 \mathrm{rpm}$, the samples were centrifuged for $8 \mathrm{~min}$ at 10,000 rpm. Each sample was tested with one concentration of $\mathrm{Cd}^{2+}$ at least six times. Based on the six measured concentrations per sample, the standard deviation was calculated and shown as 
error bars in Figure 5. A unit of $8 \mathrm{~mL}$ of the supernatant was offset with $2 \mathrm{~mL}$ of $20 \mathrm{wt} \%$ nitric acid for ICP-OES analysis. In addition, the $\mathrm{pH}$ of the supernatant was measured.

\subsection{Characterization and Analysis}

\subsubsection{H-NMR Measurements}

The chitosan samples were dissolved $0.1 \mathrm{M} \mathrm{DCl}$ in $\mathrm{D}_{2} \mathrm{O}$. Care was taken to ensure that the samples were dispersed completely. ${ }^{1} \mathrm{H}-\mathrm{NMR}$ was measured using an Avance III $500 \mathrm{MHz}$ Bruker Biospin system.

The acetylation degree (DS\%ACETYL) was calculated using the integral of the $\mathrm{CH}_{3}$ $\left(\mathrm{I}_{\mathrm{CH} 3}\right)$ group at $2.02 \mathrm{ppm}$ divided through the number of its protons (3) and the integral of the $\mathrm{H}-2$ proton $\left(\mathrm{I}_{\mathrm{H}-2}\right)$ at 3.12-3.28 ppm (Equation (1)).

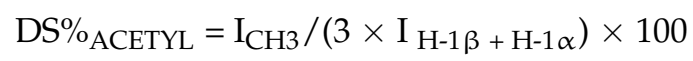

The substitution degree DS\% $\%_{N M R}$ was calculated using the sum of three integrals related to the hexanoyl residue ( $\left.\mathrm{I}_{\mathrm{CH} 3} 0.8 \mathrm{ppm} ; \mathrm{I}_{2 \times \mathrm{CH} 2} 1.3 \mathrm{ppm} ; \mathrm{I}_{\mathrm{CH} 2} 1.5 \mathrm{ppm}\right)$ dived by the number of participating protons (9) and the integral of the $\mathrm{H}-1^{\beta}$ and $\mathrm{H}-1^{\alpha}$.

$$
\mathrm{DS} \%_{\mathrm{NMR}}=\left(\mathrm{I}_{\mathrm{CH} 30.8 \mathrm{ppm}}+\mathrm{I}_{2 \times \mathrm{CH} 2} 1.3 \mathrm{ppm}+\mathrm{I}_{\mathrm{CH} 2} 1.5 \mathrm{ppm}\right) /\left(9 \times \mathrm{I}_{\mathrm{H}-1 \beta}+\mathrm{H}-1 \alpha\right) \times 100
$$

\subsubsection{FTIR Measurements}

\section{Method 1}

Powder ATR-FTIR measurements (method 1) were conducted with a Tensor 27 (Bruker Corporation, Billerica, MA, USA) device equipped with a Platinum ATR module (Bruker Corporation). ATR-FTIR spectra from powdered samples were measured by pressing either chitosan or H-chitosan-7.5 against a single reflection diamond within the Golden Gate attachment (Specac, UK), which are given in Figure S4.

To determine the substitution degree DS\%FTIR-1, the procedure of Le Tien [14] adapted from Moore et al. [24] was applied, which is based on the intensity ratio of Amide I band of N-acetyl groups and $v(\mathrm{OH})$ band of hydroxyl groups of chitosan. For the evaluation of DS\%, the following equation was used (method 1 ):

$$
\text { DS } \%_{\text {FTIR- } 1}=\mathrm{A}_{1655} / \mathrm{A}_{3450}-0.27 \times 100
$$

Thereby $\mathrm{A}_{1653}$ and $\mathrm{A}_{3450}$ are the absorbances at $1655 \mathrm{~cm}^{-1}$ and $3450 \mathrm{~cm}^{-1}$, respectively, and 0.27 specifies the acetylation in native chitosan.

\section{Method 2}

Thin films of either native chitosan or H-chitosan-, respectively, were casted onto Ge internal reflection elements (IRE, $50 \times 20 \times 2 \mathrm{~mm}^{3}$ ) from their respective solutions $(50 \mu \mathrm{L})$ in $0.001 \mathrm{M} \mathrm{HCl}$, dried at $50^{\circ} \mathrm{C}$, placed in a dedicated in situ cell and purged by $\mathrm{N}_{2}$ stream. The samples were measured in solid state with a resolution of $2 \mathrm{~cm}^{-1}$ and with 100 scans (method 2).

In method 2, modified from Moore et al. [24], the DS\% was determined based on thin chitosan films applying a line-shape analysis procedure ranging from $1700 \mathrm{~cm}^{-1}$ to $1475 \mathrm{~cm}^{-1}$ to determine the integral of the Amide I band. Thereby, this spectral section was fitted using three band components $\left(1656 \mathrm{~cm}^{-1}, 1611 \mathrm{~cm}^{-1}, 1511 \mathrm{~cm}^{-1}\right)$ with $50 \%$ Gaussian and 50\% Lorentz lineshape, respectively, and a baseline correction was undertaken (Figure S5). The DS\%FTIR-2 can be calculated based on the integral ratio between the Amide I component $\left(1656 \mathrm{~cm}^{-1}\right)$ due to acetylated/hexanoylated amino groups and the integral of $v(\mathrm{C}-\mathrm{O})$ band due to hydroxyl and ether linkages of polysaccharides (denoted saccharide band), respectively.

In the measured ATR-FTIR spectra, the ratios $(\mathrm{Q})$ of the integrals of the Amide I band at $1656 \mathrm{~cm}^{-1}$ (I $\mathrm{I}_{\text {Amide I, }}$ LSA) and the saccharide band from $1200-950 \mathrm{~cm}^{-1}$ (I ISACC $)$ were 
calculated for native chitosan (CHIT) and hexanoylated chitosan (H-CHIT), respectively (Equation (4)).

$$
\mathrm{I}_{\text {Amide I CHIT }} / \mathrm{I}_{\text {SACC CHIT }}=\mathrm{Q}_{\text {CHIT }} ; \mathrm{I}_{\text {Amide I H-CHIT }} / \mathrm{I}_{\text {SACC H-CHIT }}=\mathrm{Q}_{\mathrm{H}-\mathrm{CHIT}}
$$

It was found by Moore et al. [24] that the $\mathrm{Q}_{\mathrm{CHIT}}$ is proportional to the known acetylation degree (DS\% ${ }_{A C E T Y L}$, here $10 \%$ ) and can therefore be normalized to DS\% ${ }_{A C E T Y L}$ via a factor $n$ (Equation (5)).

$$
\mathrm{DS} \%_{\mathrm{ACETYL}}=\mathrm{Q}_{\mathrm{CHIT}} \times n \times 100=10 \%
$$

Taking the same value for factor $\mathrm{n}$ and assuming similar absorption coefficients for Amide I band related to both hexanoylated and acetylated amino groups the total degree

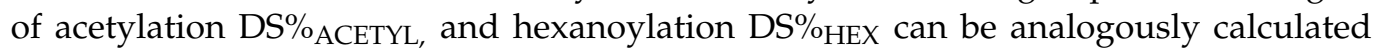
(Equation (6)).

$$
\mathrm{DS} \%_{\text {TOTAL }}=\mathrm{DS} \%{ }_{\mathrm{ACETYL}}+\mathrm{DS} \%{ }_{\mathrm{HEX}}=\mathrm{Q}_{\mathrm{H}-\mathrm{CHIT}} \times n \times 100=\mathrm{X} \% \geq 10 \%
$$

(Assuming no trans-amidification (replacing acetyl by hexanoyl groups)) DS\%FTIR-2 can be

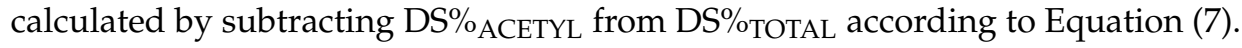

$$
\text { DS\%FTIR-2 }=\text { DS\%HEX }=\text { DS\% } \%_{\text {TOTAL }}-\mathrm{DS} \%_{\text {ACETYL }}
$$

\subsubsection{Potentiometric Titration and Zetapotential vs. $\mathrm{pH}$}

By stirring the chitosans in $2 \%$ acetic acid for $24 \mathrm{~h}$, a $1 \mathrm{~g} / \mathrm{L}$ solution was prepared. In additional cases, the solution was prepared by stirring at $50^{\circ} \mathrm{C}$ for $24 \mathrm{~h}$ and subsequently treated in an ultrasonic bath for $2 \mathrm{~h}$. The $\mathrm{pH}$ of around 3 was then adjusted to $\mathrm{pH} 1$ with $1 \mathrm{M} \mathrm{HCl}$. These solutions were subsequently diluted to $0.01 \mathrm{~g} / \mathrm{L}, 0.05 \mathrm{~g} / \mathrm{L}$, and $0.1 \mathrm{~g} / \mathrm{L}$ solutions with ultrapure water. A unit of $10 \mathrm{~mL}$ of each solution was titrated against NaPES $(0.001 \mathrm{M})$ in a particle charge detector MÜTEK PCD-04 from the company BTG Instruments

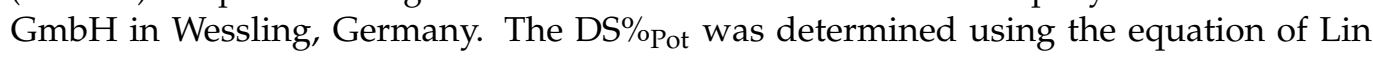
et al. [25] with $\Delta \mathrm{V}_{\mathrm{Ch}}$ and $\Delta \mathrm{V}_{\mathrm{HCh}}$ being the consumed volumes of the polyanion for native chitosan and $\mathrm{H}$-chitosan, respectively:

$$
\mathrm{DS} \%_{\text {Pot }}=\left(\Delta \mathrm{V}_{\mathrm{Ch}}-\Delta \mathrm{V}_{\mathrm{HCh}}\right) /\left(\Delta \mathrm{V}_{\mathrm{Ch}}+0.609 \times \Delta \mathrm{V}_{\mathrm{HCh}}\right) \times 100
$$

For the streaming potential vs. $\mathrm{pH}$, the solutions were titrated against a $0.1 \mathrm{~g} / \mathrm{L} \mathrm{NaOH}$ from their initial $\mathrm{pH}$ after dissolution (compare Table 2) up to a $\mathrm{pH}$ of 10 . The zeta potential was measured again using the MÜTEK PCD-04.

\subsubsection{Inductively Coupled Plasma Optical Emission Spectrometry (ICP-OES)}

ICP-OES (iCAP 7400 from Thermo Scientific, Waltham, USA) was used to determine the heavy metal ion $\left(\mathrm{Cd}^{2+}\right)$ and sulfate ion concentrations in simulated water. The standards used were: standard 1: Cd (5 mg/L); S (5 mg/L); standard 2: Cd (1 mg/L); $(1 \mathrm{mg} / \mathrm{L})$. A 4-point calibration was carried out. Therefore, the standards were diluted 1:2, 1:4, and 1:8.

\subsubsection{Nitrogen Sorption Studies}

Nitrogen sorption studies were performed using the Autosorb iQ MP from Quantachrome Instruments. All samples were dried in a vacuum oven at $90^{\circ} \mathrm{C}$ for $24 \mathrm{~h}$. The samples were activated by degassing in vacuum $\left(5 \times 10^{-10} \mathrm{mbar}\right)$ at $90^{\circ} \mathrm{C}$ for another $20 \mathrm{~h}$. The nitrogen sorption measurements were performed at $77 \mathrm{~K}$ with 100-150 mg sample. The acquired data were fitted using Brunauer Emmett Teller method (BET).

\subsubsection{Dynamic Light Scattering}

Dynamic light scattering was measured using a Zetasizer ZS device from Malvern Panalytical GmbH, Kassel, Germany. The same solutions which were subjected to the 
potentiometric titration and zeta potential vs. $\mathrm{pH}$ measurements were investigated. The solutions were additionally heated at $50{ }^{\circ} \mathrm{C}$ for $18 \mathrm{~h}$ and dissolved $2 \mathrm{~h}$ in the ultrasonic bath. The refractive index of the polymer was set to 1.530 .

\subsection{7. $\mathrm{pH}$ Measurement}

$\mathrm{pH}$ measurement was carried out with the device SevenExcellence from Mettler Toledo (Gießen, Germany) at room temperature.

\subsubsection{X-ray Diffraction Measurements (XRD)}

For XRD measurements, the chitosan powders were spread out on a Si low background sample holder (Bruker Corporation, Billerica, MA 01821, USA) and measured using a D8 DISCOVER (Bruker, Billerica, MA 01821, USA) equipped with a VÅNTEC 500 2D detector. Each sample was measured from two positions $\left(1: \Theta=10^{\circ}\right.$ and Det. $=15^{\circ} ; 2$ : $\Theta=10^{\circ}$ and Det. $=40^{\circ}$ ) for $30 \mathrm{~min}$, respectively, and the resulting diffractograms were merged.

\subsubsection{Oscillating Rotational Rheometer Measurements}

The rotational rheometer measurements were conducted using a HaakeTM MarsTM Rheometer (Thermo Fisher Scientific Inc., Waltham, MA, USA). H-chitosan or native chitosan solutions of $1 \mathrm{~g} / \mathrm{L}$ with $\mathrm{pH}=1$ were prepared and measured at $20{ }^{\circ} \mathrm{C}$ using a plate-plate $\mathrm{PP} 60^{\circ} \mathrm{Ti}$ system with a gap of $0.3 \mathrm{~mm}$. A range of 0.011 /s to $80001 / \mathrm{s}$ was measured by increasing and then decreasing the $\gamma$ in 40 steps, respectively.

\subsubsection{Thermogravimetric Analysis (TG)}

TG was performed by using the device 1 Star System from Mettler Toledo, Gießen, Germany. The measurements were carried out with approximately $7-8 \mathrm{mg}$ of chitosan in a platinum crucible. The investigated temperature range was from $25^{\circ} \mathrm{C}$ to $1000{ }^{\circ} \mathrm{C}$ with a heating rate of $10^{\circ} \mathrm{C} / \mathrm{min}$ under air atmosphere with a flow rate of $40 \mathrm{~mL} / \mathrm{min}$.

\section{Conclusions}

Within this study, the degree of substitution (DS\%) of the five H-chitosan samples, prepared at different $\mathrm{pH}$ values in the reaction mixture, was precisely calculated based on NMR spectroscopy. Based on the calculated DS\%NMR, the $\mathrm{pH}$ values of the reaction mixture had a strong influence on the final DS\% of the product and thus on the final properties. The determination of the DS\% for the H-chitosan using the commonly reported ATR-FTIR spectroscopy-based method did not lead to a coinciding result with the NMR measurements. This can be explained by the water influence on the $v(\mathrm{OH})$ band $\left(3450 \mathrm{~cm}^{-1}\right)$ and the Amide I band $\left(1655 \mathrm{~cm}^{-1}\right)$. A new method using line shape analysis for the Amide I and referencing the polysaccharide band $\left(1080 \mathrm{~cm}^{-1}\right)$ proved to render a better result, with a general deviation of $\pm 1.0 \%$ of the DS\%FTIR-2 to DS\% $\%$ NM over all $\mathrm{H}$-chitosans. Investigation with potentiometric titration showed that the DS\% $\%$ pot determined are significantly higher (average 6.7\%) than the corresponding DS\% ${ }_{N M R}$. This is presumably due to self-aggregation and solubility issues. An alteration of the standard solvation method leads to a reduction of this average value to $5.8 \%$ higher than DS\% ${ }_{N M R}$. Through DLS measurements, the self-aggregation in solution was confirmed. Further, a decrease in viscosity was observed between solutions of native chitosan to H-chitosan. The properties in the dry state were investigated by nitrogen sorption and XRD, but little to no differences were made out between modified and unmodified material.

In several overview experiments, the influence of the synthesis of the H-chitosan samples on the adsorption performance of $\mathrm{Cd}^{2+}$ ions was demonstrated. Whilst H-chitosan6.0 adsorbed the lowest amount of $\mathrm{Cd}^{2+}$, the removal by $\mathrm{H}$-chitosan-7.0, $\mathrm{H}$-chitosan-7.5, and $\mathrm{H}$-chitosan- 8.0 was between $75 \%$ and $90 \%$. These findings illustrate how even subtle differences in synthesis cause significant deviations in application-oriented properties. 
Supplementary Materials: The following are available online at https: / www.mdpi.com/article / $10.3390 / \mathrm{md} 19070385 / \mathrm{s} 1$, Figure S1. Images of the precipitation in acetone (a) and the gel-like product after filtering and washing with methanol $\left(60^{\circ} \mathrm{C}\right)(\mathrm{b})$ (here H-chitosan-6.0). Figure S2. Images of the dried products H-chitosan-6.0 (a), H-chitosan-6.5 (b), H-chitosan-7.5 (c), H-chitosan-8.0 (d). The lower $\mathrm{pH}$ values tend to form more compact fragments. Scheme S1. Hydrolysis of hexanoyl chloride as competing reaction to chitosan acylation. Scheme S2. Potential cleavage of hexanoyl functionality within the NMR tube (according to the NMR spectra, the reaction did not occur). Figure S3. ${ }^{1} \mathrm{H}-\mathrm{NMR}$ spectra of chitosan (black), H-chitosan-6.0 (red), H-chitosan-6.5 (orange), H-chitosan-7.0 (green), Hchitosan-7.5 (blue), H-chitosan-8.0 (light blue) and the respective integrals when $\mathrm{H}-2=1.000$. Scheme S3. Different glycosidic linkages within chitosan backbone leading to the two ${ }^{1} \mathrm{H}-\mathrm{NMR}$ signals $\mathrm{H}-\mathrm{1}^{\beta}$ and $\mathrm{H}-1^{\alpha}$. Figure S4. ATR-FTIR spectra (powder, $100 \mathrm{scans}, 2 \mathrm{~cm}^{-1}$ resolution) of native chitosan 90/60/A1 (black) and H-chitosan-7.5 (blue). Figure S5. Thin film ATR-FTIR spectra (method 2) of chitosan (black), H-chitosan-6.0 (red), H-chitosan-6.5 (orange), H-chitosan-7.0 (green), H-chitosan-7.5 (blue), H-chitosan-8.0 (light blue). Figure S6. Line shape analysis of H-chitosan-7.5 with measured spectrum (black), total fit (green, rms = 0.00088), Amide I (red), Amide II (yellow), $\mathrm{\delta NH}_{3}{ }^{+}$(light blue), baseline (dark blue). Figure S7. Correlation of DS\%FTIR-2 and DS\% ${ }_{N M R}$ with a maximum absolute deviation of $2.6 \%$ and an average deviation of $1.0 \%$. DS\%FTIR-2 tends to render higher DS\% than those determined via NMR. The black line indicates ideal correlation of DS\%FTIR-2 and DS\%NMR. Figure S8. Thermogravimetric analysis of chitosan (black), H-chitosan-6.0 (red), H-chitosan-6.5 (orange), Hchitosan-7.0 (green), H-chitosan-7.5 (blue), H-chitosan-8.0 (light blue). Table S1. Substitution degrees of H-chitosans determined via potentiometric titration and difference to DS\%NMR. Figure S9. DLS intensity distribution measurements $(1 \mathrm{~g} / \mathrm{L}, \mathrm{pH} 1)$ of native chitosan 90/60/A1 (black) and $\mathrm{H}$ chitosan-7.5 (blue). The distribution of the H-chitosan-7.5 shows smaller assemblies (500 nm-1 $\mu \mathrm{m})$ and larger aggregates $(5 \mu \mathrm{m}-10 \mu \mathrm{m})$ whilst chitosan only exhibits pristine polymer particles. Further, in all H-chitosan solutions, small, unsolved particles were visible that are too large in order to be measured with DLS. Figure S10. DLS volume distribution measurements $(1 \mathrm{~g} / \mathrm{L}, \mathrm{pH} 1)$ of native chitosan 90/60/A1 (black) and H-chitosan-7.5 (blue). The distribution of the H-chitosan-7.5 shows smaller assemblies $(500 \mathrm{~nm}-1 \mu \mathrm{m})$ and larger aggregates $(5 \mu \mathrm{m}-10 \mu \mathrm{m})$, while chitosan only exhibits pristine polymer particles. Further, in all $\mathrm{H}$-chitosan solutions, small, unsolved particles were visible that are too large in order to be measured with DLS. Figure S11. DLS number distribution measurements (1 g/L, pH 1) of native chitosan 90/60/A1 (black) and H-chitosan-7.5 (blue). In all $\mathrm{H}$-chitosan solutions, small, unsolved particles were visible, that are too large in order to be measured with DLS. Figure S12. Nitrogen sorption measurements. Neither native chitosan 90/60/A1 (black) nor H-chitosan (e.g., H-chitosan-7.5, blue) exhibited significant specific surface areas $\left(\mathrm{S}_{\mathrm{BET}}<3 \mathrm{~m}^{2} / \mathrm{g}\right)$; Figure S13. X-ray diffraction measurements of chitosan (black), H-chitosan-6.0 (red), H-chitosan6.5 (orange), H-chitosan-7.0 (green), H-chitosan-7.5 (blue), H-chitosan-8.0 (light blue). Figure S14. Oscillating rotational rheometer measurements of chitosan (black), H-chitosan-6.0 (red), H-chitosan6.5 (orange), H-chitosan-7.0 (green), H-chitosan-7.5 (blue), H-chitosan-8.0 (light blue). Figure S15. $\mathrm{pH}_{\mathrm{B}}-\mathrm{pH}$ of the blank value, which was measured by adding $30 \mathrm{~mL}$ of ultrapure water to the $\mathrm{H}$-chitosan sample, $\mathrm{pH}_{0}$ is the initial $\mathrm{pH}$ of the $\mathrm{CdSO}_{4}$ solution, and $\mathrm{pH}_{\text {eq }}$ is the $\mathrm{pH}$ value of the solution after the adsorption process.

Author Contributions: Conceptualization, B.R. and D.S.; methodology, B.R., M.M. and C.S.; formal analysis, B.R., M.M. and M.O.; investigation, B.R., M.M., C.S., M.O., K.H.C. and N.G.; writingoriginal draft preparation, B.R.; writing—review and editing, B.R., M.M., S.S., D.S., N.G. and C.S.; visualization, C.S., B.R. and D.S.; supervision, D.S.; project administration, S.S.; funding acquisition, S.S. All authors have read and agreed to the published version of the manuscript.

Funding: The authors gratefully acknowledge the support received from the Saxonian funding organization SAB and LfULG within the cooperative projects entitled "Development of environmentally compatible biopolymers as flocculants/adsorbents for the removal of iron and sulfate ions from surface waters" (SAB no 100377122) and "Mobile sensor systems for on-site heavy metal detection in water" (contract 33-8128/157/1), respectively.

Data Availability Statement: The data presented in this study are available in the Supporting Information and upon request from the corresponding author. 
Acknowledgments: The authors thank BioLog ${ }^{\circledR}$ Heppe GmbH from Germany for the support of the materials, discussions, and cooperativeness. Further, we thank Komber for the NMR measurements and fruitful discussions.

Conflicts of Interest: The authors declare no conflict of interest. The funders had no role in the design of the study; in the collection, analyses, or interpretation of data; in the writing of the manuscript, or in the decision to publish the results.

\section{References}

1. Fenice, M.; Gorrasi, S. Advances in Chitin and Chitosan Science. Molecules 2021, 26, 1805. [CrossRef]

2. Upadhyay, U.; Sreedhar, I.; Singh, S.A.; Patel, C.M.; Anitha, K.L. Recent Advances in Heavy Metal Removal by Chitosan Based Adsorbents. Carbohydr. Polym. 2021, 251, 117000. [CrossRef] [PubMed]

3. Borchert, K.B.L.; Steinbach, C.; Schwarz, S.; Schwarz, D. A Comparative Study on the Flocculation of Silica and China Clay with Chitosan and Synthetic Polyelectrolytes. Mar. Drugs 2021, 19, 102. [CrossRef]

4. Ghiorghita, C.-A.; Borchert, K.B.L.; Vasiliu, A.-L.; Zaharia, M.-M.; Schwarz, D.; Mihai, M. Porous Thiourea-Grafted-Chitosan Hydrogels: Synthesis and Sorption of Toxic Metal Ions from Contaminated Waters. Colloids Surf. A Physicochem. Eng. Asp. 2020, 607, 125504. [CrossRef]

5. Haufe, S.; Bohrisch, J.; Schwarz, D.; Bratskaya, S.Y.; Steinbach, C.; Schwarz, S. Flocculation Efficiency of Reacetylated Water Soluble Chitosan versus Commercial Chitosan. Colloids Surf. A Physicochem. Eng. Asp. 2017, 532, 222-227. [CrossRef]

6. Weißpflog, J.; Gündel, A.; Vehlow, D.; Steinbach, C.; Müller, M.; Boldt, R.; Schwarz, S.; Schwarz, D. Solubility and Selectivity Effects of the Anion on the Adsorption of Different Heavy Metal Ions onto Chitosan. Molecules 2020, 25, 2482. [CrossRef]

7. Xu, J.; McCarthy, S.P.; Gross, R.A.; Kaplan, D.L. Chitosan Film Acylation and Effects on Biodegradability. Macromolecules 1996, 29, 3436-3440. [CrossRef]

8. Bagheri-Khoulenjani, S.; Taghizadeh, S.M.; Mirzadeh, H. An Investigation on the Short-Term Biodegradability of Chitosan with Various Molecular Weights and Degrees of Deacetylation. Carbohydr. Polym. 2009, 78, 773-778. [CrossRef]

9. VandeVord, P.J.; Matthew, H.W.T.; DeSilva, S.P.; Mayton, L.; Wu, B.; Wooley, P.H. Evaluation of the Biocompatibility of a Chitosan Scaffold in Mice. J. Biomed. Mater. Res. 2002, 59, 585-590. [CrossRef]

10. Weißpflog, J.; Vehlow, D.; Müller, M.; Kohn, B.; Scheler, U.; Boye, S.; Schwarz, S. Characterization of Chitosan with Different Degree of Deacetylation and Equal Viscosity in Dissolved and Solid State-Insights by Various Complimentary Methods. Int. J. Biol. Macromol. 2021, 171, 242-261. [CrossRef]

11. Pestov, A.; Bratskaya, S. Chitosan and Its Derivatives as Highly Efficient Polymer Ligands. Molecules 2016, 21, 330. [CrossRef]

12. Moore, G.K.; Roberts, G.A.F. Determination of the degree of N-acetylation of chitosan. In Proceedings of the First International Conference on Chitin/Chitosan; MIT Sea Grant Program. Massachusetts Institute of Technology: Cambridge, MA, USA; pp. 421-429.

13. Layek, B.; Singh, J. N-Hexanoyl, N-Octanoyl and N-Decanoyl Chitosans: Binding Affinity, Cell Uptake, and Transfection. Carbohydr. Polym. 2012, 89, 403-410. [CrossRef]

14. Le Tien, C.; Lacroix, M.; Ispas-Szabo, P.; Mateescu, M.-A. N-Acylated Chitosan: Hydrophobic Matrices for Controlled Drug Release. J. Control. Release 2003, 93, 1-13. [CrossRef]

15. Zong, Z.; Kimura, Y.; Takahashi, M.; Yamane, H. Characterization of Chemical and Solid State Structures of Acylated Chitosans. Polymer 2000, 41, 899-906. [CrossRef]

16. Naidoo, S.; Nomadolo, N.; Matshe, W.M.R.; Cele, Z.; Balogun, M. Exploring the Potential of N-Acylated Chitosan for the Removal of Toxic Pollutants from Wastewater. IOP Conf. Ser. Mater. Sci. Eng. 2019, 655, 012047. [CrossRef]

17. Han, J.; Guenier, A.-S.; Salmieri, S.; Lacroix, M. Alginate and Chitosan Functionalization for Micronutrient Encapsulation. J. Agric. Food Chem. 2008, 56, 2528-2535. [CrossRef]

18. Piegat, A.; Goszczyńska, A.; Idzik, T.; Niemczyk, A. The Importance of Reaction Conditions on the Chemical Structure of N,O-Acylated Chitosan Derivatives. Molecules 2019, 24, 3047. [CrossRef] [PubMed]

19. Neugebauer, W.A.; Neugebauer, E.; Brzezinski, R. Determination of the Degree of N-Acetylation of Chitin-Chitosan with Picric Acid. Carbohydr. Res. 1989, 189, 363-367. [CrossRef]

20. Curotto, E.; Aros, F. Quantitative Determination of Chitosan and the Percentage of Free Amino Groups. Anal. Biochem. 1993, 211, 240-241. [CrossRef] [PubMed]

21. Vårum, K.M.; Antohonsen, M.W.; Grasdalen, H.; Smidsrød, O. Determination of the Degree of N-Acetylation and the Distribution of N-Acetyl Groups in Partially N-Deacetylated Chitins (Chitosans) by High-Field n.m.r. Spectroscopy. Carbohydr. Res. 1991, 211, 17-23. [CrossRef]

22. Hexanoic Acid. Available online: https://bmrb.io/metabolomics/mol_summary/show_data.php?id=bmse000351 (accessed on 16 May 2021).

23. Clayden, J.; Greeves, N.; Warren, S. Organische Chemie, 2nd ed.; Springer Spektrum: Heidelberg, Germany, 2013; ISBN 978-3-64234715-3.

24. Moore, G.K.; Roberts, G.A.F. Determination of the Degree of N-Acetylation of Chitosan. Int. J. Biol. Macromol. 1980, 2, 115-116. [CrossRef] 
25. Lin, A.; Chen, J.; Liu, Y.; Deng, S.; Wu, Z.; Huang, Y.; Ping, Q. Preparation and Evaluation of N-Caproyl Chitosan Nanoparticles Surface Modified with Glycyrrhizin for Hepatocyte Targeting. Drug Dev. Ind. Pharm. 2009, 35, 1348-1355. [CrossRef]

26. Cho, Y.; Kim, J.T.; Park, H.J. Size-Controlled Self-Aggregated N-Acyl Chitosan Nanoparticles as a Vitamin C Carrier. Carbohydr. Polym. 2012, 88, 1087-1092. [CrossRef]

27. Pa, J.-H.; Yu, T.L. Light Scattering Study of Chitosan in Acetic Acid Aqueous Solutions. Macromol. Chem. Phys. 2001, 202, 985-991. [CrossRef]

28. WHO. Guidelines for Drinking-Water Quality, 3rd ed.; Volume 1-Recommendations. Available online: http://www.who.int/ water_sanitation_health/publications/gdwq3rev/en/ (accessed on 29 April 2021).

29. Hasan, S.; Krishnaiah, A.; Ghosh, T.K.; Viswanath, D.S.; Boddu, V.M.; Smith, E.D. Adsorption of Divalent Cadmium (Cd(II)) from Aqueous Solutions onto Chitosan-Coated Perlite Beads. Ind. Eng. Chem. Res. 2006, 45, 5066-5077. [CrossRef] 